\title{
Analysis on the Import of Sino-Japanese Neologism to China during Qing Dynasty
}

\author{
Yidan Xiong ${ }^{1, *}$

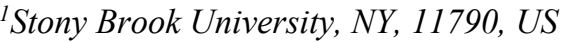 \\ *Corresponding author. Email: rrrribbon@outlook.com

\begin{abstract}
The paper contributes a cultural and social aspects of exploring the import of Sino-Japanese. The paper aims to find out the reason why new-created Sino-Japanese were successfully imported and popularized in China during Qing dynasty. The paper used the method of textual analysis. The result shows that Sino-Japanese were widely adopted in China at that time because of political reason and its strong practicability.
\end{abstract}

Keywords: Sino-Japanese, Sino-Japanese War, Meiji restoration, westernization, translation

\section{INTRODUCTION}

Sino-Japanese are broadly used nowadays in China. Several researches studied the linguistic aspects of Sino-Japanese, indicating that Sino-Japanese were formed of recombined Chinese character and how it benefited people until today. This paper, instead, explores the cultural and social aspect of importing of Sino-Japanese that provide a new sight of Sino-Japanese Studies. The paper, with a method of textual analysis, aims to deeply explore the reason why China adopted Sino-Japanese neologism created by Japan instead of using originally created compounds. It is predicted that the reasons could be political power, naturally imported because of the close distance and improvement of language. This paper reveals that language is not just effected by linguistic factors but also political and humanity factors, in order to promotes a better way to explore the change of a language system.

\section{TYPES OF SINO-JAPANESE}

Sino-Japanese refers to the portion of the Japanese vocabulary that originated in Chinese or has been created from Chinese elements. Ancient China's large territory and advanced culture led Chinese to give an enormous influence on Japanese. At the time of their first contact, the Japanese language had no writing system, while Chinese had a written language and a great deal of academic information. Providing new concepts along with Chinese words to express them, Chinese became the language of science, learning and religion [10]. Therefore, some grammatical structures and patterns can also be identified as Sino-Japanese. After they became very skilled in using Chinese, Japanese utilized these Kanji to create new phrases borrowed from western concepts. There are four types of modern Japanese: “和語”,which refers to native Japanese language; “漢語”, which refers to the borrowed classic Chinese characters or created characters by these classic Chinese characters; “外来 語”, which refers to the western phrases; “混種語”, which refers to the phrases that are made by the above mentioned three types. And Sino-Japanese is basically originated from these 4 types of Japanese [10]. In summary, Sino-Japanese words are made up of two parts: Kanbun, which is also called Kango, and loanwords.

The first part of Sino-Japanese is Kanbun, which is also the origin of Japanese. Kanbun is the classic Chinese, the earliest written language to be used in Japan, from Heian period to the mid-20th century. They were originally called "Hanzi" in Chinese. First they were imported to Korean Peninsula, and then they made their way to Japan by classic Chinese religious texts. During the Heian period, Japanese already had their own language, which was not Chinese, neither the Japanese they speak today. For the purpose of unifying, Japanese decided to give each Kanji character both Chinese readings and Japanese readings instead of converting them to Chinese.

The other part of Sino-Japanese is loanwords. They were imported into Japan and were translated during Meiji Restoration in the 1860s. Meiji Restoration was a 
political revolution that ended the military government called Tokugawa shogunate and also the Edo period. The main theme of the revolution was reform and rebellion, not only in military, but also in economics, culture and technology since Japan had been isolated for nearly two centuries. By the threat of western expand and encroachment, the westernization of Japan started. Adopting the slogan "Enrich the country, strengthen the army" and the policy of opening the door to foreign technology. Thus, a large number of systematized theories were imported.

The imported concepts described the western history, law, system, science, education and philosophy. Chinese characters were almost the same as Japanese translated one, they were just different in simplified version and traditional version. The words Japanese chose to describe the concepts were better and precise than the characters Chinese scholars had chosen. When the Meiji Restoration began, it was late Qing dynasty in China.

The translation of Japanese works became a social trend after first Sino-Japanese War in China just like Western learning during Meiji Restoration in Japan. Students from China were sent to Japan to learn the language and also the knowledge about all aspects, and it was very effective. Feng implies that there is a statistic description of this phenomenon comparing to the previous situation before the first Sino-Japanese War from 1850-1899, out of the 576 kinds of western learning translation, books from the West were $65 \%$ while those from Japan only 15\%; from 1901-1904, out of the 533 kinds of translation, books from the West were only $25 \%$ while those from Japan were $60 \%$ [4]. During the decade at the end of the Qing Dynasty, the translation works from Japan became the main reading material in the Chinese society. With all the books and new concepts, the Chinese-character Japanese words were imported into China. They were accepted easier than the Western language words because there were the same or similar characters in Sino-Japanese. As a result, more and more number of Sino-Japanese words were introduced and soon people started to use the characters [9].

\section{ANALYSIS OF FORMATION OF THE SINO-JAPANESE}

\subsection{Analysis from the perspective of Japan}

In the late nineteenth century, Western power started to divide the world. Under the fierce offensive of this power, China, Japan and other Asian countries became semi-feudal and semi-colonial countries and signed series of unequal treaties. In order to get rid of colonial oppression and achieve national independence and self-improvement, all countries had adopted a series of measures and launched a reform movement to learn from the Western modern industrial civilization. The reform of Meiji Restoration in Japan had a great significance in the history of the world, and became a successful model for transplanting Western civilization, learned by other countries.

"Rangaku" (蘭学), which could be translated to "Dutch learning", was introduced to Japan by the Netherlands during the period of the lock-up period and mainly after the reform of the government. It was based on Western science and technology and also contained various forms of Western knowledge. It was the earliest contact between Japanese and Western civilization. With the opening of the shogunate, there were also "English studies", "legal studies", "ethics", "aesthetics", etc., collectively referred to as "foreign studies" [1].

The starting point of Rangaku is medicine, and was developed from the center of medicine. The first to introduce Japan was surgery, and later medical disciplines such as internal medicine were gradually introduced. According to the development and translation of basic medicine, it was anatomy, physiology, pathology and so on. Later, Rangaku broke through the scope of medicine and produced various disciplines such as pharmacy, botany, physics, and chemistry. Due to language restrictions, it was difficult for foreign scholars to be directly introduced to Japan. In this period, the means of Rangaku and foreign studies were mainly translated into Japanese by Rangaku and foreign scholars, which were spread and developed in Japan [1].

For the purpose of training people, the Shogunate first established a foreign academic institution. In the reform of the end of the curtain period, the shogunate set up some foreign academic institutions according to actual needs, with a view to cultivating foreign scholars as their own. During the Ansei reform period, the reform leader Abe Masahiro gathered a group of Confucian scholars, orchid scientists and artillerist for coast defense issues, and founded the Institute of Foreign Studies in 1855. The main task was to understand the situation of Western countries, to translate European and American books and cultivate the translation skills of Japanese students. Second, in 1857, the institution started to recruit students to study French, Germany, English and subjects about science. They focused on understanding and comparing the military, technology and industry of Western countries. The Shogunate sent international students to study abroad for the purpose of learning Western culture and technologies. This was a meaningful step that had a huge impact on Meiji Restoration. Most of the translated resources were academic writings. The new phrases appeared, and there were concepts that they had never heard of. When Japanese tried to translate the new concepts in academic writings, they used the Kanji characters they had to recombine them and created new 
phrases in Kanji. That was the time when the loanwords were created. They were deliberately coined, adapted during that time, they made the majority of Sino-Japanese words utilized today not only in Japan, but in China [5].

At that time, going to Western learning institutions became very popular among students [1]. However, the Shogunate officials had their identity restrictions for the students that get into the school. The students had to be a Samurai or an identity above it and had to pass the Confucianism test that the institution gave, in case that they would not be affected by the Western law system, economic system, philosophy, education, which is a way of avoiding people to have new thoughts and belief [1].

In terms of educational content, the Shogunate imitated Western-style education, attached importance to practical skills, popularized knowledge of science, arithmetic, geometry, chemistry, preliminary physics, history, geography, self-cultivation, the national language, composition drawing, gymnastics and singing in elementary school, and later quited the traditional Confucian education. Higher level elementary schools also set foreign language courses in addition to the above standard subjects.

After the Opium War, Japan was sensitive to the situation that Western countries invaded East Asian countries. The government became more aware of Western military superiority and Western industrial technology advantage, it is necessary to cultivate scientific research talents and specialized technical talents in Japan. Therefore, the Meiji government emphasized the training of higher level education, dispatched a larger number of overseas students, learned from the development experience of German higher education. While China's foreign affairs faction was devoted to creating "objects", Japan had focused on training on "person" who created the objects.

\subsection{Analysis from the perspective of China}

During the late Qing Dynasty (1894), the first Sino-Japanese War broke. China was colonized by Japan, politics were corrupted, and commoners were suffering from poverty and post-war life. Because of the defeat of the Sino-Japanese War, the Qing government realized that westernization was an inevitable process to get stronger, they sent a large number of foreign students to Japan. In the second year of the Sino-Japanese War, the Qing government sent 13 overseas students to Japan. According to the statistics investment by Mito Hideyuki, there were 8,000 Chinese students studying in Japan in 1906. In the period between the Opium War and the First Sino-Japanese War, westernization was focused on advanced science and technology. With the rising appeal for political reform, the focus of the western learning was shifted from science and technology to the political system and social culture of constitutional monarchy, which required a lot more amount of resources to translate.

Because of the shock by the defeat, the Chinese intelligentsia saw the decaying of the Qing government under the corrupted feudal autocracy and the rise of Japan after the Meiji Restoration. Some scholars like Zhidong Zhang, Youwei Kang and Qichao Liang realized the limitations of the western learning translation just by traditional Chinese. They knew the translation was not enough for the Westernization Movement. Seeing the success of the Meiji Restoration, they started to focus on translating Japanese academic writings and text books. There were already a large number of works translated during the Meiji Restoration [9].

\section{ATTITUDES OF SCHOLARS IN CHINA}

There were two groups of people that had opposite attitudes toward Sino-Japanese: scholars who agree with the decision to import Sino-Japanese words and scholars who disagree with it. Qichao Liang was a Chinese modern philosopher, politician, educator, historian and writer, one of the leaders of the Hundred Days Reform (1898), a representative of Chinese modern reformists and New Legalists. After the failure of the Hundred Days Reform, he left Beijing and was exiled to Japan with Youwei Kang. Liang actively advocated the use of Japanese and utilized it as an intermediary of text that could learn advanced ideas and scientific theories of the Western concepts by adopting the method of translating Japanese [10].

The 14 years of exile in Japan is one of the most productive and most active periods of Liang with his published articles. Although Liang had Confucianism education backgrounds, he was deeply influenced by Fukuzawa Yuichi, who agreed that people in Japan should refuse Confucianism, instead, he supported Westernization, focusing on being independent and democratic. Liang thought Confucianism should not be abandoned but to combine the good side of western political ideas and Chinese tradition. He learned more about Western modern thoughts through Japanese translation of a large number of Western books [8]. In particular, the "Xinmin Theory" Liang proposed in New Citizen had brought great influence to modern Chinese society. The proposals for new knowledge, new ideas, and new culture, led by the "Xinmin Theory" had been greatly influenced by translations, Japanese works, newspapers, magazines. Liang suggested that Chinese and Japanese languages had the same root. He constantly absorbed the Western civilization ingested by Japan. The new vocabulary and concepts were continuously gathered. New Citizen had become the most influential magazine to import Sino-Japanese and popular among students in China [2]. 
On the other hand, Fu Yan used traditional Chinese characters to translate Western concepts. He strongly disagrees with the ideas of using Sino-Japanese to educate people in Chinese. He even said in his letter this decision would be a disaster following the end of the examination system which encouraged the use of the eight-legged essays [6]. Qing government also showed a rejecting attitude to Japanese-imported words and criticized them severely, because they thought the possibility that Sino-Japanese could replace the traditional classic characters, which would be bad for the official examinations that the Qing government usually gave to students each year [7]. Sino-Japanese words were imported to China before Yan had started to translate new terms. According to Yan's translated books, there were 482 new terms, but only 56 of them were adopted today [12]. The competition between Sino-Japanese and China-created words lasted from the late Qing Dynasty until the early Republican period.

\section{CHINA-CREATED COMPONENTS AND THE REASON OF ITS FAILURE}

The process of absorbing concepts of Western civilization through Japan in China was proposed by Qichao Liang, mainly in his published book Learning Japanese Through Chinese. Liang edited and summarized the ways to learn Japanese in the book, the book was the first textbook to learn Japanese in China. The book listed the syllabary and hiragana, katakana, and the corresponding roman pronunciation. It not only introduced the terms such as nouns, verbs, adjectives, adverbs, auxiliary verbs, but also introduced the terms like present tense, the past tense, the future tense, and the change of suffix of Japanese verbs. The book listed the demonstrative pronouns, a large number of contextual words and detailed the usage and meaning of some vascular words [11]. The second part of Learning Japanese Through Chinese was a dictionary. The newly created phrase using Kanji characters (e.g., 自由) and the idioms commonly (e.g., 言マデナク) used by Japanese were explained.

In contrast, Fu Yan advocated direct translation from Western literatures and materials, he insisted that the second translation from Japanese would change the original meaning, so he held a negative attitude towards Sino-Japanese and tried to create a large number of Chinese new phrases instead. Yan utilized a lot of traditional Chinese and they were difficult for people to understand, since people started to use vernacular Chinese. He adopted single words and transliteration while Sino-Japanese used combined words [7]. He translated sociology to “群学” (qun xue). Japanese translated it to “社会学"(she hui xue). For this case, he used “社会” frequently. But there were still many cases that he was less satisfied with. For example, the word "rights" in English. For the translation of Japanese, it was “権利” (kennri), in simplified Chinese, it would be “权利” (quanli). Yan Fu was unhappy about it, he thought the Japanese translation had totally changed the original meaning and “权利” was used as a Chinese terms with negative meanings to translate an English word with positive meanings [13]. In the letter Yan wrote to Liang, Yan had trouble choosing the most precise character to translate. He related the Kanji to other traditional Chinese characters which people only studies in an old textbook. For example, "職” and "直”, Yan read in the Book of Odes that "直" should be read as "職", so he thought the translation should use "直" but actually these two words had different meanings commonly. The deeper thinking of choosing the characters of Yan can be the reason that they were difficult for other people to understand.

Instead, Japan had three main ways to translate Western concepts, the first one was borrowing Western words directly, the second one was translate words into native Japanese, and the third way was the creation of Sino-Japanese. The third one was a way of "recycling" of Chinese characters, which means the recombination of Kanji characters originated from China but endowed them with new meanings. Except for the academic words that could be adopted at school or in professional field, there were many more created new phrases by Japanese than people expected. Telephone, which is called "denwa"(電話) in Japanese and "dian hua"(电 话)in Chinese. The pronunciation of them are very similar. This is a typical example of the recombination of kanji characters to create new phrase. "Dian" (电)means "electricity" and "hua"(话) means to talk, it basically describes what telephone is used for - talk to others through electronics. There were a group of phrases that had original meaning in Chinese, but changed after the imported Sino-Japanese phrases. For example, “人気”"(ninnki) and “人气”(ren qi), they have the same character, but the meaning was different. "人 气” (ren qi) in Chinese originally meant the temperament and emotion of human. Instead, in Japanese, it meant popularity. After the popularization of Sino-Japanese, these kinds of phrases had their double meanings in China.

\section{THE RESULT OF SINO-JAPANESE NEOLOGISM WERE IMPORTED TO CHINA}

The recombination of Sino-Japanese was easier for people to understand, and before the China-created components were accepted by people, the system of using Sino-Japanese had been developed completely in China. The failure of China-created components was foreseeable. The development of Sino-Japanese is the 
carrier of Japanese thought and culture from generation to generation, and it is also a true portrayal of the rise of modern Japan's national power. In the early modern times, Japan was still a toddler, and many Chinese translations were introduced into Japanese, laying the foundation for the development of Japanese culture. During the Meiji Restoration, the Japanese created new words by themselves and it helped to grow their national power. After the Sino-Japanese War, Japan completely surpassed China and began to reverse transmitting its language. Sino-Japanese naturally "reshapes" modern Chinese intentionally or unintentionally.

\section{CONCLUSION}

This paper explored the reason why China adopted Sino-Japanese neologism created by Japan instead of using originally created compounds. The result shows that there are two main reasons:

First, because of the political colonization of Japan in China, the new concepts and new recombined words of different fields during Meiji restoration had been brought into China and they were imported successfully because of the promotion of scholars.

Second, Sino-Japanese were easier for people to understand because it recombined single Chinese words into a new phrases. Sino-Japanese improved the obscure of Classical Chinese and brought Vernacular Chinese to the next level.

The integration of Sino-Japanese, improvement and change of Sino-Japanese still need to be studied. Surveys and interviews about how people in China divided into different age groups think about the Sino-Japanese phrases can be added to the research. The future research will mainly focus on the variation of Sino-Japanese and the local factors of influence.

\section{REFERENCES}

[1] An, Ke. Science and Technology Policy Reform and Influence During the Period of Meiji Restoration in Japan. 2016. Shanxi University, Master dissertation.

[2] Chen, Zejia. "The Introduction of Japanese-Coined Chinese by Liang Qichao." Journal of Hebei University (Philosophy and Social Science), vol. 40, no. 4 , Jul. 2015 , pp. $72-75$.

[3] Espesset, Grégoire. “Traditional Chinese Knowledge before the Japanese Discovery of Western Science in Gabor Lukacs' Kaitai Shinsho \& Geka Sōden." Review of Kaito Shinsho: The Single Most Famous Japanese Book of Medicine \& Geka Sōden: An Early Very Important Manuscript on Surgery, by Lukacs Gabor. East Asian Science, Technology, and Medicine, 2014, p. 113-128.
[4] Feng, Tianyu. The Origin of New Words_Culture Interaction Between China and Japan and the Formation of Modern Chinese Terms. Zhong Hua Press, 2004, pp. 441.

[5] Frellesvig, Bjarke. "A History of the Japanese Language." Cambridge University Press, 2010, pp. 147-148.

[6] Hao, haozi. The Collected Works of Lin Shu and Yan Fu. Rotary Club for National Learning, 1909, pp. 1.

[7] Huang, Max K.W. "The War of Neologisms: The Competition between the Newly Translated Terms Invented by Yan Fu and by the Japanese in the Late Qing." China and Its Others: Knowledge Transfer through Translation, edited by André James St., Xiaoyan Peng, 2012, pp. 51-71.

[8] Shi, Shaobo. "On the Perspective of Fukuzawa Yukichi Confucianism and Western Learning." Guanzi Journal, vol. 2, no.2, 2018, pp. 94-99.

[9] Teng, Changjiang. On the Interaction Between the Social Thought Transformation and the Loanword Introduction After the First Sino-Japanese War. 2009. Nanjing Agricultural University, Master dissertation.

[10] Tu, Yanqian. The formation and development of Sino-Japanese during Meiji Restoration. 2008. University of International Business and Economics, Master dissertation.

[11] Xiao, Lang, and Sun Yingying. 'Liang Qichao's Learning Japanese through Chinese and Its Influence on the Intellectual Circle in Late Qing Dynasty and the Early Republic of China." Journal of Zhejiang University (Humanities and Social Science), vol. 47, no. 1, Jan. 2017, pp. 57-66.

[12] Xiong, Yuezhi. Dissemination of Western Learning to the East and Late Qing Society. Shanghai Renmin Press, 1994, pp. 700-701.

[13] Yan, Fu, and Wang Shi. Collected Works of Yan Fu. Zhong Hua Press, 1986. 